\title{
HC-Pro silencing suppressor significantly alters the gene expression profile in tobacco leaves and flowers
}

\author{
Arto J Soitamo*, Balaji Jada and Kirsi Lehto
}

\begin{abstract}
Background: RNA silencing is used in plants as a major defence mechanism against invasive nucleic acids, such as viruses. Accordingly, plant viruses have evolved to produce counter defensive RNA-silencing suppressors (RSSs). These factors interfere in various ways with the RNA silencing machinery in cells, and thereby disturb the microRNA (miRNA) mediated endogene regulation and induce developmental and morphological changes in plants. In this study we have explored these effects using previously characterized transgenic tobacco plants which constitutively express (under CaMV 355 promoter) the helper component-proteinase (HC-Pro) derived from a potyviral genome. The transcript levels of leaves and flowers of these plants were analysed using microarray techniques (Tobacco $4 \times 44$ k, Agilent).

Results: Over expression of HC-Pro RSS induced clear phenotypic changes both in growth rate and in leaf and flower morphology of the tobacco plants. The expression of 748 and 332 genes was significantly changed in the leaves and flowers, respectively, in the HC-Pro expressing transgenic plants. Interestingly, these transcriptome alterations in the HC-Pro expressing tobacco plants were similar as those previously detected in plants infected with ssRNA-viruses. Particularly, many defense-related and hormone-responsive genes (e.g. ethylene responsive transcription factor 1, ERF1) were differentially regulated in these plants. Also the expression of several stress-related genes, and genes related to cell wall modifications, protein processing, transcriptional regulation and photosynthesis were strongly altered. Moreover, genes regulating circadian cycle and flowering time were significantly altered, which may have induced a late flowering phenotype in HC-Pro expressing plants. The results also suggest that photosynthetic oxygen evolution, sugar metabolism and energy levels were significantly changed in these transgenic plants. Transcript levels of S-adenosyl-L-methionine (SAM) were also decreased in these plants, apparently leading to decreased transmethylation capacity. The proteome analysis using 2D-PAGE indicated significantly altered proteome profile, which may have been both due to altered transcript levels, decreased translation, and increased proteosomal/protease activity.

Conclusion: Expression of the HC-Pro RSS mimics transcriptional changes previously shown to occur in plants infected with intact viruses (e.g. Tobacco etch virus, TEV). The results indicate that the HC-Pro RSS contributes a significant part of virus-plant interactions by changing the levels of multiple cellular RNAs and proteins.
\end{abstract}

\section{Background}

Plant virus infections cause a large variety of different disease symptoms in susceptible plants. Viruses invade and utilize the central biosynthetic routes of the host cells, but plants have evolved specific means to resist virus attacks. RNA silencing is one of the main adaptive

\footnotetext{
*Correspondence: artsoi@utu.fi

Department of Biochemistry and Food Chemistry, Molecular Plant Biology, University of Turku, Vesilinnantie 5, Turku, 20014, Finland
}

defence mechanism against transposons, transgenes and also pathogenic nucleic acids i.e. viruses [1-3]. During viral RNA replication in plants, the viral ssRNA molecules produce dsRNA structures, which are processed by Dicer-like ribonucleases (DCL; an RNAse III-like enzyme) into small interfering RNAs (siRNAs). These assemble with argonaute (AGO) protein(s) to form the RNA-induced silencing complexes (RISC) that are able to specifically cleave RNAs sharing sequence identity
C Biomed Central

(c) 2011 Soitamo et al; licensee BioMed Central Ltd. This is an Open Access article distributed under the terms of the Creative Commons Attribution License (http://creativecommons.org/licenses/by/2.0), which permits unrestricted use, distribution, and reproduction in any medium, provided the original work is properly cited. 
with the original viral RNA (PTGS, post-transcriptional gene silencing) [4]. To counteract this host defence mechanism, viruses encode for specific RSSs. These counteract the degradation of viral RNA, but they also interfere with plants own small RNA (smRNA) biosynthesis and silencing-mediated gene regulation. It has been shown that the virus symptoms are induced at least to some extent by these factors, and that severe (symptom-like) developmental defects can be caused in vegetative and reproductive organs by their transgenic expression [5-13].

Proteinase1/Helper component-proteinase (P1/HCPro) encoded by the 5 ' proximal region of the TEV was one of the first RSSs characterized [14]. Since then, features of the HC-Pro RSS of different potyviruses have been characterized in detail in several papers $[5,6,11,13,15-18]$. They have been shown to affect differently the accumulation of various miRNA molecules and miRNA target transcripts $[5,6,11]$. Both miRNA processing and function are impaired in transgenic P1/HC-Pro expressing lines, and consequently both the miRNA/ miRNA* processing intermediates and the miRNA target messages accumulate in these transgenic plants. More recently, it has been shown that the P1/HC-Pro directly binds and sequesters miRNA/miRNA* molecules [16]. It has been also shown that HC-Pro interacts with the $26 \mathrm{~S}$ proteasomes [19] and inhibits their RNA endonuclease activity [20]. The plant proteasomes function as antiviral defence system by degrading virus RNAs, and potyviral HC-Pro counteracts also this anti-viral defence system by decreasing their endonuclease activity [20].

Most of the previous studies of the HC-Pro RSS have been performed using Arabidopsis thaliana as a model plant. Transgenic tobacco plants (a natural host of Potato Virus $Y$, PVY) which constitutively express PVY-derived HC-Pro, have been previously produced and characterized in our laboratory [10]. Here we have analysed by microarray techniques (Tobacco $4 \times 44 \mathrm{k}$, Agilent) the transcript profiles of the leaves and flowers of these tobacco plants, and compared them to the previously published transcriptome analysis of virus-infected $A$. thaliana [15,21-26]. Array results indicated significant transcriptional changes both in the leaf and flower samples, especially in genes encoding proteins involved in plants defence, as well as in genes related to stress response, circadian and flowering time responses and energy metabolism. Most of these changes are similar with changes reported in the plants infected with intact RNA viruses, e.g. TEV and Cucumber mosaic virus strain $\mathrm{Y}(\mathrm{CMV}-\mathrm{Y})$.

\section{Results}

\section{Experimental design and differential gene expression}

The transgenic tobacco line expressing the $\mathrm{HC}$-Pro gene of PVY strain $\mathrm{N}$ under constitutive expression of CaMV
$35 \mathrm{~S}$ promoter [10] was used in this study. Wild type tobacco (wt) plants and plants containing empty transformation vector (pBIN61) were used as controls for the transgenic line [10]. No phenotypic differences were detected between these two types of control plants (Figure 1A, 1B and 1D).

The expression of HC-Pro RSS in tobacco plants caused clear phenotypic changes in leaves, stems and flowers as earlier described [10]. The growth of transgenic HC-Pro expressing plant was clearly retarded, and the appearance of the plants varied from short stems to almost a bushy like appearance (Figure 1D). Also the flowering time was clearly delayed, as the transgenic plants typically flowered two to three months later than

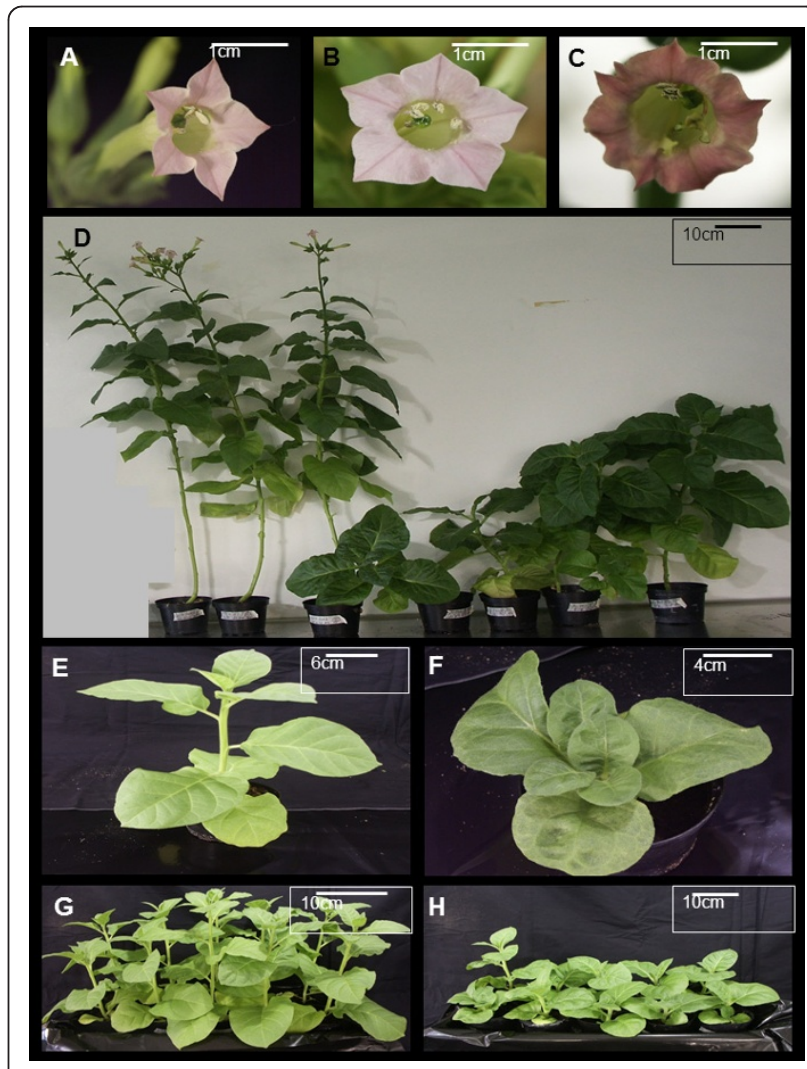

Figure 1 Phenotypes observed in Nicotiana tabacum plants expressing HC-Pro transgene. A typical morphology of flowers is indicated in the upper part of the figure (A-C). A wild type tobacco flower is presented in $\mathbf{A}$, a vector control flower (pBIN61) in $\mathbf{B}$ and a transgenic HC-Pro expressing flower in $\mathbf{C}$. Phenotypes of two wild type tobacco plants at the flowering state (on the left) and one vector control plant (pBIN61, in between of these wild type plants) and four transgenic HC-Pro expressing plants are presented in $\mathbf{D}$. One representative of one-month old wild type tobacco plant (E) and one transgenic HC-Pro expressing plant (F) demonstrating differences in growth and leaf morphology. A growing pattern of 10 one-month old wild type tobacco plants $(\mathbf{G})$ and 10 transgenic HC-Pro expressing plants $(\mathbf{H})$ are presented at the bottom of the figure 
the wild type plants. The morphology of the flower was variable, but it often differed from the wild type. The petals were often fused together and the color of the petals was changed from pink to pale pink or variegated. The anther filaments were often converted to extra petals and sometimes they were divided (Figure 1C). The transgenic plants produced only small amount of viable seeds.

The expression level of HC-Pro transgene varied in tobacco plants and affected the phenotype of these transgenic plants; the higher HC-Pro expression levels the more severe developmental defects [10]. Out of ten plants, three plants were chosen for the microarray analysis based on typical, average phenotype of HC-Pro plants (see Figure 1) and on average transgene HC-Pro expression (Additional file 1).

The microarray was performed according to Agilent's standard protocols and quality controls for total RNA, and for cDNA labeling (see Methods). After data normalization of leaf and flower samples, statistical parameters for genes were calculated. Statistical differences between the two types of controls (wt and pBIN61) and HC-Pro transgenic leaf and flower samples were tested by using Student's t-test $(\mathrm{p}<0.05)$. It turned out that the two types of control plants had a very similar expression pattern, with only a few genes being differentially expressed between them (Additional files 2 and 3). Therefore both control samples could be used together to make a total of six biological control replicates. Finally, the six normalized gene expression intensity values of control samples were compared against three normalized intensity values of the HC-Pro expressing transgenic plants to detect whether gene expression values would differ significantly $(\mathrm{p}<0.05)$ from each other. A two-fold cut of value for up- or down- regulated genes were selected. Based on these comparisons 368 genes were found up-regulated and 380 genes down-regulated in leaves of the HC-Pro expressing plants, making together 748 differently expressed genes in the leaves. However, only 121 genes were up-regulated and 211 genes down-regulated in the HC-Pro expressing flower samples (Table 1).

The microarray results were verified by reverse transcription-quantitative PCR (RT-qPCR) of some significantly up- and down-regulated genes both in the leaf and flower samples (Table 2). Similar expression data was obtained for these selected genes using both these methods.

The construction of the microarray probes has been based mostly on tobacco EST, cDNA and mRNA sequences, and it was necessary to verify the gene names provided by Agilent. Thus, the genes that were found to be significantly up- or down- regulated was reannotated using the BLAST program (NCBI). Additional information about the putative gene functions was obtained from recently sequenced tomato and potato genomes, as compared to the previous annotation solely based on A. thaliana genomic information. A summary of manually re-annotated and functionally characterized genes is presented in Table 1. Functional characterization was based on similar categorization presented by Marathe et al. [23].

\section{HC-Pro transgene causes virus infection-like changes in gene expression and induces defence-related genes}

The microarray results (Table 1) clearly demonstrated that expression of HC-Pro in transgenic plants mimicked the effects of virus infections at the transcriptional level [15,21-26], as similar groups of genes were modulated in these plants as in Arabidopsis model plants infected by TEV [15] or CMV-Y [23].

Many defense and stress related genes were induced in both leaves and flowers of the HC-Pro expressing transgenic plants (Table 3). Many of these genes are regulated either by ethylene or jasmonic acid regulated pathways and can be induced by external treatment of these plant hormones. They can also be induced in transgenic Arabidopsis plants by over expression of the ethylene response transcription factor 1 (ERF1), which integrates signals from ethylene and jasmonic acid pathways in plant defense responses [27]. The expression of the ERF1 mRNA was up-regulated more than five times in leaves, and more than two times in flowers of the HC-Pro expressing transgenic tobacco plants (Table 4). In addition, ethylene response transcription factor 4 (ERF4), a negative regulator of jasmonic acid-responsive defence related genes [28] was clearly down-regulated in these plants. Accordingly, several jasmonic acid, ethylene or salicylic acid responsive transcription factors, like WIZZ (a JA-induced WRKY protein), Jasmonic acid 2 (a NAC transcription factor) and ethylene responsive transcription factor 3 (ERF3) were over expressed in HC-Pro expressing transgenic plants (Table 4). In flowers, the ERF1 transcription factorinduced genes include many genes encoding Avr9/Cf9 rapidly elicited (ACRE) proteins. Further annotation of these $A C R E$ genes revealed that they were involved in both defense and stress responses, encoding for example proline rich proteins (e.g. cereal-type alpha-amylase inhibitors), lipid transfer proteins, seed storage proteins, late embryogenesis proteins (LEA), Avirulence-like protein 1, as well as AP2-type transcription factors (ACRE111B) (Additional files 4, 5 and 6).

\section{HC-Pro induced differential expression of stress response genes}

Pathogen or virus infections in plants induce differential expression of stress responsive genes [15,22]. Our array results indicated differential expression of many genes 
Table 1 An overview of microarray results demonstrating differentially expressed transcripts in leaves and flowers in HC-Pro expressing plants

\begin{tabular}{|c|c|c|c|c|}
\hline Functional characterization & HC-Pro leaf & HC-Pro leaf & HC-Pro flower & HC-Pro flower \\
\hline Expression of genes & (UP) & $(\mathrm{DOWN})$ & (UP) & $(\mathrm{DOWN})$ \\
\hline Defence related & 7 & 17 & 21 & 12 \\
\hline $\mathrm{ROI}$ related & 12 & 12 & 2 & 6 \\
\hline Kinases and phosphatases & 10 & 20 & 1 & 12 \\
\hline Transcriptional regulators & 21 & 28 & 9 & 7 \\
\hline Protein degradation and proteases & 14 & 7 & 9 & 4 \\
\hline Lipases and hydrolases & 10 & 8 & 0 & 4 \\
\hline Transporters & 5 & 20 & 2 & 24 \\
\hline HSPs & 7 & 7 & 1 & 0 \\
\hline Signalling & 7 & 2 & 2 & 3 \\
\hline Cell wall related & 16 & 11 & 9 & 29 \\
\hline Stress related & 28 & 37 & 8 & 7 \\
\hline Protein synthesis related & 9 & 4 & 1 & 1 \\
\hline Photosynthesis related & 31 & 42 & 3 & 15 \\
\hline RNA binding & 16 & 2 & 3 & 1 \\
\hline Interesting miscellaneous & 120 & 101 & 21 & 65 \\
\hline Unknown function & 55 & 62 & 29 & 21 \\
\hline Total & 368 & 380 & 121 & 211 \\
\hline
\end{tabular}

Table represents functional characterization of genes whose expression was up- or down- regulated more than two-fold. Statistical significance was tested by using Student's-test $(p<0.05)$.

responsive to cold, salt and dehydration even though the tobacco plants were grown under normal growth conditions (Table 3). In addition, genes in phenyl propanoid pathway (leading from phenylalanine to anthocyanins and lignins) were significantly down regulated (e.g. chalcone synthase and leucoanthosyanidin dioxygenase) [29], whereas terpenoid synthesis (leading from DOXP pathway to carotenoids and brassinosteroids) were significantly up-regulated (e.g. DSX1 and DSX2).
Altered expression of cell wall biosynthesis related genes in HC-Pro expressing plants

Plant cell wall, the first barrier of defense against invading pathogens, is composed of cellulose microfibrils crosslinked by hemicellulose, pectin, lignin and extensin. Pectins are one of the main components in cell wall against invading pathogens. Endo-polygalacturonase (PG), one of the enzymes secreted at the early stages of infection, depolymerizes the homogalacturonan, the main component of

Table 2 Verification of microarray results using RT-qPCR

\begin{tabular}{|c|c|c|c|c|}
\hline \multicolumn{2}{|c|}{ Leaf (up-regulated transcripts) } & \multirow{2}{*}{$\begin{array}{c}\text { Microarray } \\
\text { Fold }\end{array}$} & \multirow{2}{*}{$\begin{array}{c}\text { RT-qPCR } \\
\text { Fold }\end{array}$} & \multirow[b]{2}{*}{ s.e } \\
\hline EST/mRNA & Description & & & \\
\hline EH620344 & Arabidopsis thaliana FKF1 (FLAVIN-BINDING, KELCH REPEAT, F BOX 1) & 12.45 & 18.36 & 2.97 \\
\hline EH615198 & Nicotiana tabacum nictaba (NT1) mRNA Jasmonic acid methyl ester and ethylene-induced mRNA & 6.41 & 10.1 & 2.90 \\
\hline FG156808 & Nicotiana tabacum 1-D-deoxyxylulose 5-phosphate synthase (DXS) mRNA & 3.61 & 3.30 & 0.27 \\
\hline \multicolumn{5}{|c|}{ Leaf (down-regulated transcript) } \\
\hline AY741503 & Nicotiana tabacum S-Adenosyl- L-methionine methyl transferase mRNA (SAMT) $(p=0.067)$ & 0.44 & 0.35 & 0.11 \\
\hline \multicolumn{5}{|c|}{ Leaf (non-regulated transcripts) } \\
\hline EB450395 & Arabidopsis thaliana ARPC3 (actin-related protein C3) & 1.09 & 1.00 & 0.00 \\
\hline X67159 & Nicotiana tabacum pectate lyase mRNA & 0.98 & 1.01 & 0.01 \\
\hline \multicolumn{5}{|c|}{ Flower (up-regulated transcripts) } \\
\hline EB438380 & Solanum lycopersicum Trypsin and protease inhibitor, mRNA & 2.86 & 3.50 & 0.94 \\
\hline EB683763 & Nicotiana tabacum mRNA for P-rich protein NtEIG-C29 & 2.03 & 2.10 & 0.28 \\
\hline FG157361 & Nicotiana tabacum mRNA for RAV & 2.14 & 1.60 & 0.19 \\
\hline \multicolumn{5}{|c|}{ Flower (down-regulated transcript) } \\
\hline AY772945 & Nicotiana tabacum pectin methylesterase mRNA & 0.36 & 0.19 & 0.16 \\
\hline
\end{tabular}

Some clearly up- or down-regulated genes of leaf and flower samples were tested. Statistical significance was tested using Student's t-test ( $p<0.05$ ). Fold change is indicated as a ratio of HC-Pro/WT calculated from normalized median intensity values $(n=3)$. Standard error of mean (s.e.) is also calculated for RT-qPCR values. 
Table 3 Up- or down-regulation of transcripts in HC-Pro expressing plants

\begin{tabular}{|c|c|c|c|c|c|}
\hline \multicolumn{3}{|c|}{ Defense related transcripts Leaf } & \multicolumn{3}{|c|}{ Stress related transcripts Leaf } \\
\hline $\mathrm{EST} / \mathrm{mRNA}$ & Fold & Description & $\mathrm{EST} / \mathrm{mRNA}$ & Fold & Description \\
\hline EH615198 & 6.4 & Nicotiana tabacum nictaba mRNA (NT1) & TA14956_4097 & 3.8 & Tamarix Putative stress-responsive protein \\
\hline FG636567 & 3.8 & Nicotiana tabacum mRNA for P-rich protein NtElG-C29 & FG156808 & 3.6 & $\begin{array}{l}\text { Nicotiana tabacum 1-D-deoxyxylulose 5- } \\
\text { phosphate synthase mRNA (DXS1) }\end{array}$ \\
\hline EB433973 & 2.8 & $\begin{array}{l}\text { Parsley PCPR1-3 mRNA for pathogenesis-related protein } \\
\text { type B }\end{array}$ & CV016057 & 2.9 & $\begin{array}{l}\text { Arabidopsis thaliana cold-regulated } 413- \\
\text { plasma membrane } 2 \text { mRNA COR413-PM2 }\end{array}$ \\
\hline S44869 & 2.4 & Nicotiana tabacum Endochitinase A precursor & EB441160 & 2.9 & $\begin{array}{l}\text { Solanum lycopersicum dxs2 gene for } 1 \text { - } \\
\text { deoxy-D-xylulose } 5 \text {-phosphate synthase }\end{array}$ \\
\hline X12739 & 2.1 & $\begin{array}{l}\text { Nicotiana tabacum Pathogenesis-related protein } \mathrm{R} \text { major } \\
\text { form precursor }\end{array}$ & EB435759 & 2.8 & $\begin{array}{l}\text { Ipomoea nil In04 mRNA for caffeoyl-CoA O- } \\
\text { methyltransferase }\end{array}$ \\
\hline TA14009_4097 & 0.5 & Nicotiana tabacum Chitinase 134 & TA12600_4097 & 2.8 & $\begin{array}{l}\text { Solanum tuberosum Low temperature and } \\
\text { salt responsive protein }\end{array}$ \\
\hline EB425556 & 0.5 & Arabidopsis thaliana beta-1,3-glucanase-related mRNA & EB451519 & 2.8 & $\begin{array}{l}\text { Solanum lycopersicum geranylgeranyl } \\
\text { pyrophosphate synthase } 1 \text { (GGPS1) }\end{array}$ \\
\hline EH624302 & 0.5 & Arabidopsis thaliana callose synthase 1 mRNA CALS1 & EB445705 & 2.7 & Vitis vinifera RD22-like protein mRNA \\
\hline \multicolumn{3}{|c|}{ Defense related transcripts Flower } & DV161729 & 2.1 & $\begin{array}{l}\text { Arabidopsis thaliana snf1-related protein } \\
\text { kinase } 2.2 \text {, SNRK2.2 }\end{array}$ \\
\hline FG167555 & 3.8 & $\begin{array}{l}\text { Nicotiana tabacum Avr9/Cf-9 rapidly elicited protein 111B } \\
\text { (ACRE111B) AP2-DOMAIN }\end{array}$ & FG633784 & 2.0 & $\begin{array}{l}\text { Solanum lycopersicum anthocyanin } \\
\text { acyltransferase mRNA, Jasmonic acid } \\
\text { inducible }\end{array}$ \\
\hline AB041516 & 3.5 & Nicotiana tabacum P-rich protein EIG-I30 & EB680165 & 0.3 & $\begin{array}{l}\text { Arabidopsis thaliana SIP3 (SOS3- } \\
\text { INTERACTING PROTEIN 3) }\end{array}$ \\
\hline TA14524_4097 & 3.0 & $\begin{array}{l}\text { Nicotiana tabacum Avr9/Cf-9 rapidly elicited protein } 65 \\
\text { (ACRE65) mRNA, }\end{array}$ & EB433693 & 0.4 & $\begin{array}{l}\text { Arabidopsis thaliana AFP1 (ABI FIVE BINDING } \\
\text { PROTEIN) }\end{array}$ \\
\hline FG640154 & 2.6 & $\begin{array}{l}\text { Nicotiana tabacum mRNA for basic pathogenesis-related } \\
\text { protein Thaumatin }\end{array}$ & TA14058_4097 & 0.4 & $\begin{array}{l}\text { Ipomoea nil CHS-D mRNA for chalcone } \\
\text { synthase }\end{array}$ \\
\hline FG635113 & 2.5 & $\begin{array}{l}\text { Nicotiana tabacum Avr9/Cf-9 rapidly elicited protein } 20 \\
\text { (ACRE20) mRNA; EF-hand calcium binding protein }\end{array}$ & EB439278 & 0.4 & $\begin{array}{l}\text { Nicotiana tabacum NtERD10B mRNA for } \\
\text { dehydrin }\end{array}$ \\
\hline TA13004_4097 & 2.2 & $\begin{array}{l}\text { Nicotiana tabacum mRNA for hin1 gene: Harpin inducing } \\
\text { protein }\end{array}$ & EB437158 & 0.5 & $\begin{array}{l}\text { Ricinus communis leuco-anthocyanidin } \\
\text { dioxygenase mRNA }\end{array}$ \\
\hline TA15227_4097 & 2.1 & $\begin{array}{l}\text { Nicotiana tabacum Avr9/Cf-9 rapidly elicited protein 76; } \\
\text { NDR1/HIN1 }\end{array}$ & DW003496 & 0.5 & Ricinus communis Salt-tolerance protein \\
\hline \multirow[t]{2}{*}{ AB127582 } & 2.1 & $\begin{array}{l}\text { Nicotiana tabacum Harpin inducing protein 1-like } 18 \\
\text { DOMAIN: LEA_2 }\end{array}$ & EB438355 & 0.5 & $\begin{array}{l}\text { Arabidopsis thaliana ATHK1 (histidine kinase } \\
1 / \text { osmosensor) }\end{array}$ \\
\hline & & & EB438355 & 0.5 & $\begin{array}{l}\text { Catharanthus roseus cold inducible histidine } \\
\text { kinase } 1 \text { (iK1) mRNA }\end{array}$ \\
\hline
\end{tabular}

HC-Pro expression alters significantly $(\mathrm{p}<0.05)$ expression of several genes related to defense and stress responses.

Fold change is indicated as a ratio of HC-Pro/WT calculated from normalized median intensity values $(n=3)$.

pectin, by cleaving the $\beta-1,4$ glycosidic bonds between the galacturonic acid units [30]. The following oligosaccharides may activate plant defence responses such as synthesis of phytoalexins, lignin and ethylene, expression of proteinase inhibitors and $\beta$-1, 3-glucanase and production of reactive oxygen species [31]. Irshad and coworkers [32] have recently provided a new picture of cell wall dynamics in elongating cells by analysing cell wall proteomics and by identifying several new cell wall-related proteins. Interestingly, our microarray reveals that many of these cell wallassociated genes are diffentially expressed in HC-Pro expressing transgenic plants (Table 5). The gene encoding polygalacturonase inhibitor protein precursor (PGIP) was significantly up-regulated [30], whereas the gene encoding polygalacturonase (PG) was down-regulated. Similarily, pectin methyl esterase inhibitor (PMEI) transcripts were upregulated whereas $P M E$ transcripts were down-regulated in leaves. However, transcripts of $P M E I$ were not significantly altered in flowers but transcripts of $P M E$ and pectin lyases were significantly down-regulated in them (Table 5). Also other genes related to wall dynamics [32], e.g. genes encoding proteases and protease inhibitors (cysteine proteinase, serine carboxypeptidase and trypsin inhibitor), structural proteins (proline rich proteins), and other proteins acting on carbohydrates (alpha-expansins, expansin-like A, chitinase and callose synthetase) were differentially expressed in the HC-Pro expressing plants (Table 5).

\section{Flowering time is delayed in HC-Pro transgenic plants}

Transgenic HC-Pro expressing plants had a late flowering phenotype when compared to wild type tobacco plants. Therefore, it was not surprising that expression of the circadian clock genes and genes involved in flower induction was altered in the HC-Pro expressing transgenic plants 
Table 4 Up- or down-regulation of transcripts in HC-Pro expressing plants

\begin{tabular}{|c|c|c|c|c|c|}
\hline \multicolumn{3}{|l|}{ Leaf } & \multicolumn{3}{|l|}{ Leaf } \\
\hline EST/mRNA & Fold & Description & EST/mRNA & Fold & Description \\
\hline NP917355 & 5.1 & Nicotiana tabacum mRNA for ERF1 & TA18922_4097 & 0.2 & Solanum lycopersicum CONSTANS 1 \\
\hline FG145666 & 4.6 & Nicotiana tabacum RAV mRNA & EB427139 & 0.2 & $\begin{array}{l}\text { Populus nigra PnLHY2 mRNA for transcription } \\
\text { factor LHY }\end{array}$ \\
\hline EH620499 & 3.4 & Arabidopsis thaliana PLPB (PAS/LOV PROTEIN B) & TA16366_4097 & 0.3 & $\begin{array}{l}\text { Glycine max MYB transcription factor MYB118 } \\
\text { (MYB118) mRNA }\end{array}$ \\
\hline AB063574 & 2.5 & Nicotiana tabacum WRKY DNA-binding protein & EB434774 & 0.3 & $\begin{array}{l}\text { Arabidopsis thaliana ATHB-7 (At-HOMEOBOX } \\
7 \text { ) }\end{array}$ \\
\hline FG637951 & 2.4 & $\begin{array}{l}\text { Nicotiana sylvestris nserf3 gene for ethylene-responsive } \\
\text { element binding } 3\end{array}$ & EB435512 & 0.3 & $\begin{array}{l}\text { Arabidopsis thaliana CDF1 (CYCLING DOF } \\
\text { FACTOR 1) }\end{array}$ \\
\hline DV159714 & 2.4 & Medicago truncatula GIGANTEA protein & TA14638_4097 & 0.4 & $\begin{array}{l}\text { Castanea sativa Late elongated hypocotyl } \\
(\mathrm{LHY})\end{array}$ \\
\hline EB433445 & 2.4 & $\begin{array}{l}\text { Arabidopsis thaliana mRNA for RNA polymerase sigma } \\
\text { subunit SigD SIG4 (SIGMA FACTOR 4) }\end{array}$ & EB428015 & 0.4 & $\begin{array}{l}\text { Nicotiana sylvestris Ethylene-responsive } \\
\text { transcription factor } 4 \text { (ERF4) }\end{array}$ \\
\hline DW002999 & 2.2 & $\begin{array}{l}\text { Arabidopsis thaliana KTF1 (KOW DOMAIN CON-TAINING } \\
\text { TRANSCRIPTION FACTOR 1) }\end{array}$ & FG641901 & 0.4 & $\begin{array}{l}\text { Arabidopsis thaliana basic helix-loop-helix } \\
(\mathrm{bH} L \mathrm{H}) \text { protein }\end{array}$ \\
\hline DV162575 & 2.1 & Arabidopsis thaliana Transcription initiation factor IIB-2 & FG642227 & 0.4 & $\begin{array}{l}\text { Solanum tuberosum MADS transcriptional } \\
\text { factor (Stmads11) mRNA }\end{array}$ \\
\hline TA15319_4097 & 2.0 & Nicotiana tabacum WIZZ, JA-induced WRKY mRNA & DV999024 & 0.4 & $\begin{array}{l}\text { Populus trichocarpa SAUR family protein } \\
\text { (SAUR23), mRNA, Auxin responsive }\end{array}$ \\
\hline Flower & & & TC4480 & 0.4 & $\begin{array}{l}\text { Solanum tuberosum Jasmonic acid 2, NAC- } \\
\text { transcription factor }\end{array}$ \\
\hline TA13711_4097 & 2.6 & Nicotiana tabacum RAV mRNA & TA17590_4097 & 0.5 & $\begin{array}{l}\text { Oryza sativa WRKY transcription factor } 65 \\
\text { (WRKY65) gene }\end{array}$ \\
\hline DV999109 & 2.3 & $\begin{array}{l}\text { Nicotiana tabacum Ethylene-responsive transcription } \\
\text { factor } 1 \text { (ERF1) }\end{array}$ & EB446153 & 0.5 & $\begin{array}{l}\text { Tobacco mRNA for TGA1a DNA-binding } \\
\text { protein; bZIP transcription factor }\end{array}$ \\
\hline TA15319_4097 & 2.1 & Nicotiana tabacum WIZZ JA-induced WRKY mRNA & EB424613 & 0.5 & Camellia sinensis MYB transcription factor \\
\hline TA16951_4097 & 2.1 & $\begin{array}{l}\text { Arabidopsis thaliana ASL37 mRNA for ASYMMETRIC } \\
\text { LEAVES2-like } 37 \text { protein }\end{array}$ & DW004709 & 0.5 & $\begin{array}{l}\text { Lycopersicon esculentum AREB-like protein } \\
\text { mRNA; bZIP transcription factor; }\end{array}$ \\
\hline AF193771 & 2.0 & $\begin{array}{l}\text { Nicotiana tabacum DNA-binding protein } 4 \text { (WRKY4) } \\
\text { mRNA }\end{array}$ & & & \\
\hline
\end{tabular}

HC-Pro expression alters significantly $(p<0.05)$ expression of several transcription factor genes.

Fold change is indicated as a ratio of HC-Pro/WT calculated from normalized median intensity values $(n=3)$.

$[33,34]$. The genes encoding a blue light receptor FKF1, GIGANTEA and PLPB, a PAS/LOV protein, were all upregulated, whereas the gene encoding CYCLING DOF FACTOR1 (CDF1) protein for the induction of CONSTANS (CO) gene was down-regulated (Table 6). The down-regulation of the $C O$ gene may have affected the regulation of photoperiodic FLOWERING LOCUS (FT) gene and caused the late flowering phenotype. Moreover, EARLY flowering 4 (ELF4) is also known to regulate oscillatory properties of circadian clock, and it's over expression induces late flowering phenotype under long day conditions in Arabidopsis [35]. The ELF4 transcripts were also clearly up-regulated in HC-Pro expressing plants (Table 6). Also several AP2-related transcription factors were up-regulated both in leaf and flower tissues, i.e. ERF1 and RAV2 (also known as TEMPRANILLO [36].)

\section{Proteases and proteosomal degradation}

HC-Pro protein of PVY has a special function in cleaving the polyprotein into functional viral proteins. Based on its functional domains the $\mathrm{HC}$-Pro protein is characterized as a cysteine-type endopeptidase and thioredoxin. However, it is not known whether expression of this protein in transgenic tobacco plants could induce proteolytic activity and reversible oxidation of two cysteine thiol groups in tobacco cells. Our microarray data showed that several genes encoding protease inhibitors were induced suggesting that this response was induced to resist protease and proteasomal degradation (Table 7). These included trypsin and metallocarboxy-peptidase IIa proteinase inhibitors, and many of these proteases are known to be cell wall-associated proteins $[32,37]$. Also proteasome-related genes like ubiquitin ligases were induced.

\section{Gene expression related to photosynthesis}

Microarray results also indicated altered gene expression for enhancing energy production (ATP). Mitochondrial and chloroplastic ATP synthetase genes were both upregulated. Genes encoding starch degradation (alphaamylase and alpha-glucan water dikinase) were up-regulated, and genes encoding starch synthesis were down- 
Table 5 Up- or down-regulation of cell wall related transcripts in HC-Pro transgenic plants

\begin{tabular}{|c|c|c|}
\hline \multicolumn{3}{|l|}{ Leaf } \\
\hline EST/mRNA & Fold & Description \\
\hline TA16228_4097 & 6.1 & Nicotiana tabacum mRNA for DC1.2 homologue, PME inhibitor \\
\hline FG195661 & 6.0 & Nicotiana tabacum cysteine-rich extensin-like protein-4 \\
\hline DV157917 & 2.7 & Lycopersicon esculentum xyloglucan endotransglycosylase LeXET2 (LeXET2) \\
\hline EB425603 & 2.4 & Solanum Iycopersicum Polygalacturonase inhibitor protein precursor, PGIP \\
\hline AB176522 & 2.4 & Glucosyltransferase NTGT4 related cluster \\
\hline AB176524 & 2.4 & Nicotiana tabacum, Glycosyltransferase NTGT5b \\
\hline TA13721_4097 & 2.4 & Solanum tuberosum Expansin-like protein precursor \\
\hline EB444508 & 2.3 & Phaseolus vulgaris Hydroxyproline-rich glycoprotein \\
\hline CV017677 & 2.1 & Nicotiana tabacum mRNA for pectin methylesterase \\
\hline DV160974 & 0.3 & Nicotiana tabacum alpha-expansin precursor (Nt-EXPA4) mRNA \\
\hline EB426691 & 0.4 & Ricinus communis cinnamoyl-CoA reductase, putative, mRNA, lignin biosynthesis \\
\hline TA19759_4097 & 0.4 & Arabidopsis thaliana Putative cellulose synthase \\
\hline FG152217 & 0.5 & Arabidopsis thaliana polygalacturonase (PG) \\
\hline EB424698 & 0.4 & Arabidopsis thaliana pectin acetyl estrase \\
\hline FG179245 & 0.4 & Arabidopsis thaliana pectin acetylesterase family protein \\
\hline \multicolumn{3}{|l|}{ Flower } \\
\hline EH623866 & 3.9 & Solanum lycopersicum Xyloglucan endotrans-glucosylase-hydrolase XTH3 \\
\hline EB450248 & 2.3 & Lycopersicon esculentum Xyloglycan endotransglycosylase precursor \\
\hline FG644421 & 2.2 & Ricinus communis Glycine-rich cell wall protein \\
\hline EB428200 & 0.3 & Petunia integrifolia Pectinesterase precursor \\
\hline BP133533 & 0.3 & COBRA-like protein 10 precursor related cluster \\
\hline EB428683 & 0.3 & Nicotiana tabacum pectate lyase Nt59 \\
\hline TC6632 & 0.3 & Arabidopsis thaliana Cellulose synthase \\
\hline EB427886 & 0.3 & Vigna radiata Pectinacetylesterase precursor \\
\hline FG155250 & 0.3 & Nicotiana tabacum pectin methylesterase (PPME1) mRNA \\
\hline
\end{tabular}

Transcripts encoding pectin, lignin and extensin synthesis and degradation were altered significantly $(p<0.05)$ in HC-Pro transgenic plants. Fold change is indicated as a ratio of HC-Pro/WT calculated from normalized median intensity values $(n=3)$.

regulated (Table 8 ). These results are related to the reduced amount of starch granules in leaves of the HCPro expressing plants, and this was confirmed by visual observation of starch pellets during thylakoid preparation (Figure 2), and by direct quantitation of starch from the leaf samples (Additional file 7). Genes involved in glycolysis, like phosphoenolpyruvate (PEP) carboxylase and its activating kinase were also down-regulated. Sugar transporters and isomerases were up-regulated, whereas sucrose-phosphate synthase (SPS) gene was

Table 6 The expression of circadian and flowering time related genes in transgenic HC-Pro plants

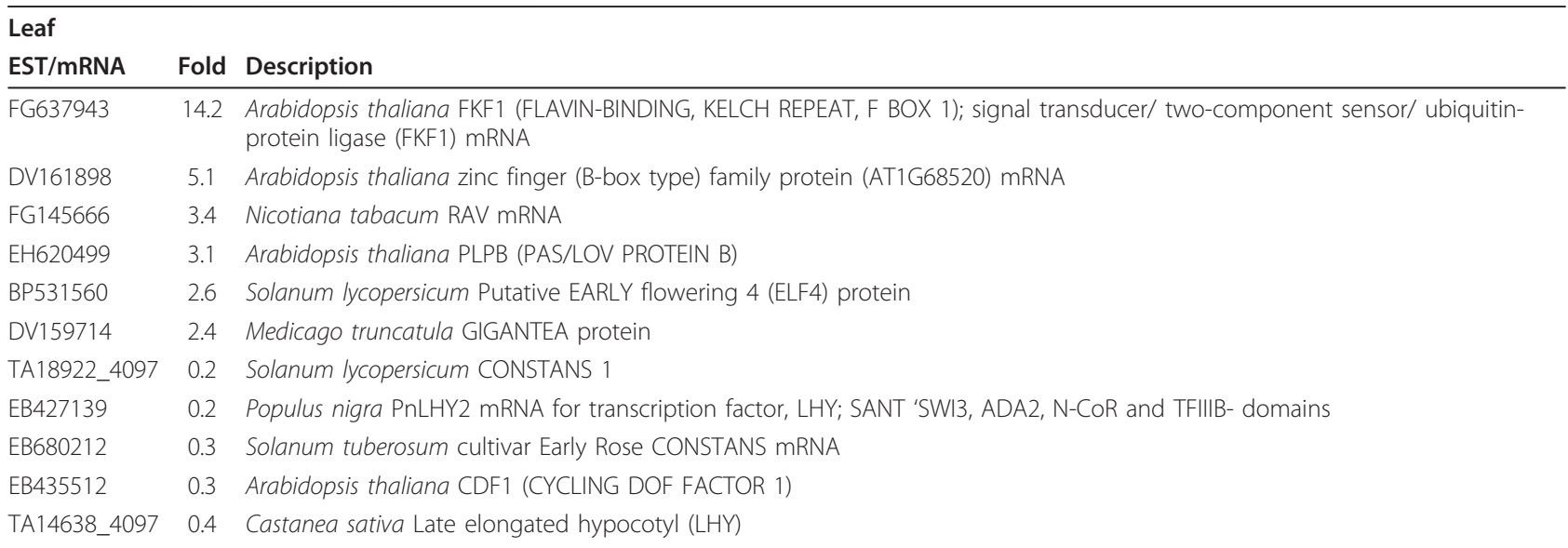




\begin{tabular}{|c|c|c|}
\hline \multicolumn{3}{|l|}{ Leaf } \\
\hline EST/mRNA & Fold & Description \\
\hline EB438380 & 27.5 & Solanum lycopersicum unknown trypsin inhibitor-like protein precursor \\
\hline FG637943 & 14.2 & Arabidopsis thaliana FKF1 (FLAVIN-BINDING, KELCH REPEAT, F BOX 1) \\
\hline TA13877_4097 & 10.9 & Nicotiana glutinosa putative proteinase inhibitor mRNA \\
\hline TA12601_4097 & 4.6 & Acyrthosiphon pisum ubiquitin ligase E3 \\
\hline CV019298 & 3.3 & Solanum tuberosum metallocarboxypeptidase inhibitor lla \\
\hline CV018626 & 3.0 & Ricinus communis Serine carboxypeptidase, putative, mRNA, AT3 g45010/F14D17_80 \\
\hline FG643489 & 2.8 & Arabidopsis thaliana AtPP2-B13 (Phloem protein 2-B13); carbohydrate binding F-box protein 3 \\
\hline TA17751_4097 & 2.6 & Development and cell death domain, the KELCH repeats and ParB domain. \\
\hline CV018465 & 2.4 & Subtilisin-like protease related cluster \\
\hline BP133434 & 2.4 & Ricinus communis protein binding protein, putative, mRNA (ubiquitin protein ligase) \\
\hline TA17959_4097 & 2.3 & Mirabilis jalapa, ubiquitin ligase \\
\hline FG635491 & 2.1 & Ricinus communis RING-H2 finger protein ATL2B, putative, mRNA \\
\hline BP530000 & 2.1 & Kelch repeat-containing F-box protein-like \\
\hline FG137301 & 2.1 & Tomato ATP-dependent protease (CD4A) \\
\hline TA18536_4097 & 0.2 & Arabidopsis thaliana LKua-ubiquitin conjugating enzyme, F19K23.12 protein \\
\hline CV019784 & 0.4 & Lycopersicum esculentum mRNA for serine protease, SBT1 \\
\hline EB429242 & 0.4 & LIM, zinc-binding; Ubiquitin interacting motif; Peptidase M, neutral zinc metallopeptidases, \\
\hline
\end{tabular}

Statistical significance was tested using Student's t-test $(p<0.05)$.

Fold change is indicated as a ratio of HC-Pro/WT calculated from normalized median intensity values $(n=3)$.

down-regulated. In addition, carbon assimilation-related genes large subunit of rubisco $(R B C L)$ and rubisco subunit binding beta were both up-regulated. At the same time, the genes encoding chlororespiration (CCR4) and cyclic electron transport proteins (PGR5) were clearly down-regulated possibly allocating more electrons to linear electron transport. All these sugar metabolismrelated gene expression alterations imply carbon metabolism imbalance, and indicate higher glucose over sucrose content in cells.

As there were clear changes in expression of genes encoding proteins involved in the photosynthetic light and dark reactions, some photosynthetic parameters were measured. Light responsive curve of photosystem II (PSII) activity (Figure 3) indicated decreased PSII oxygen evolution activity in HC-Pro expressing leaves. On the other hand, the reduced amount of starch in leaves of the HC-Pro expressing plants may also indicate problems in carbon fixation in chloroplast stroma (Figure 2).

It is well documented that carbon metabolism affects gene expression $[38,39]$. Our results indicated that many dark induced $(D I N)$ genes as well glucose/sucrose regulated genes were differentially regulated in $\mathrm{HC}$-Pro expressing plants. E.g. asparagine synthetase (DIN6) and $\alpha$-amylase genes were up-regulated and SPS, nitrate reductase $(N R)$ and adenylate kinase $(A M K)$ genes were down-regulated (Table 8). Also the genes encoding sugar balance sensor molecules were differentially regulated. The histidine-kinase 1 like (ATHK1-like) gene involved in water balance sensing and dehydration was down-regulated, whereas the SNF1-RELATED PROTEIN KINASE (SNRK) gene involved in sugar metabolite stress-responsive gene regulation was up-regulated in the HC-Pro expressing plants (Table 3).

As metabolism-related gene expression suggests energy (ATP) depletion in HC-Pro expressing plants, a high AMP/ATP ratio is expected. This probably affects several ATP demanding processes like production of SAM $[40,41]$. Recycling of adenosine is of vital importance in this process. However, we did not detect any changes in the expression of gene encoding adenosine kinase (ADK), but instead we detected change in expression of two genes encoding enzymes equilibrating adenine nucleotides, namely $A M K$ and Ade phosphoribosyltransferase $(A P T)$ (Table 8). AMK transcripts were down-regulated whereas $A P T$ transcripts were up-regulated in HC-Pro expressing leaves. These both affect balance between adenine, AMP and ADP. In addition, genes encoding SAM synthase and transferase (SAMT) were clearly down-regulated (Table 8). SAM is the key compound for all transmethylation reactions like methylation of pectin, DNA, RNA, histones and polyamine synthesis. Moffatt et al. 2002 [40] have created adk sense and antisense mutant lines to inactivate ADK enzyme in transgenic Arabidopsis and found both developmental abnormalities (a compact, bushy appearance of plants with small, rounded and waxy leaves) and reduced transmethylation activities (e.g reduced level of 


\begin{tabular}{|c|c|c|c|c|c|}
\hline \multicolumn{3}{|l|}{ Leaf } & \multicolumn{3}{|l|}{ Leaf } \\
\hline EST/mRNA & Fold & Description & $\mathrm{EST} / \mathrm{mRNA}$ & Fold & Description \\
\hline EH620909 & 3.6 & $\begin{array}{l}\text { Nicotiana tabacum photosystem I reaction center } \\
\text { subunit (PsaN) mRNA }\end{array}$ & NP916903 & 3.6 & $\begin{array}{l}\text { Nicotiana tabacum asparagine synthetase } \\
\text { (DARK INDUCIBLE 6) (DIN6) mRNA }\end{array}$ \\
\hline EB427609 & 3.5 & Rubisco subunit binding-protein beta subunit-like & EH618866 & 2.2 & $\begin{array}{l}\text { Arabidopsis thaliana ADENINE } \\
\text { PHOSPHORIBOSYL TRANSFERASE } 1 \text { (APT1) } \\
\text { mRNA }\end{array}$ \\
\hline FG146265 & 2.8 & $\begin{array}{l}\text { Solanum tuberosum alpha-glucan water dikinase } \\
\text { (SEX1) }\end{array}$ & FG176614 & 2.0 & $\begin{array}{l}\text { Arabidopsis thaliana DIN10 (DARK INDUCIBLE } \\
\text { 10) }\end{array}$ \\
\hline TA22161_4097 & 2.8 & $\begin{array}{l}\text { Nicotiana sylvestris ATP synthase subunit beta, } \\
\text { chloroplastic }\end{array}$ & FG140432 & 2.6 & $\begin{array}{l}\text { Nicotiana benthamiana asparagine synthetase } \\
\text { (DIN6) mRNA }\end{array}$ \\
\hline TA12737_4097 & 2.7 & $\begin{array}{l}\text { Nicotiana plumbaginifolia ATP synthase subunit alpha, } \\
\text { mitochondrial }\end{array}$ & EB435670 & 0.3 & $\begin{array}{l}\text { Arabidopsis thaliana NRT1.5 (NITRATE } \\
\text { TRANSPORTER) mRNA }\end{array}$ \\
\hline TA11967_4097 & 2.6 & $\begin{array}{l}\text { Nicotiana sylvestris Ribulose bis-phosphate carboxylase } \\
\text { large subunit }\end{array}$ & TA12496_4097 & 0.4 & $\begin{array}{l}\text { Solanum tuberosum Granule-bound starch } \\
\text { synthase 1, chloroplast precursor }\end{array}$ \\
\hline DQ460148 & 2.6 & $\begin{array}{l}\text { Solanum tuberosum glucose-6-phosphate/phosphate } \\
\text { translocator } 2\end{array}$ & CV017874 & 0.4 & $\begin{array}{l}\text { Nicotiana langsdorffii } \times \text { Nicotiana sanderae } \\
\text { sucrose-phosphate synthase } 2 \text { (SPS) mRNA }\end{array}$ \\
\hline EB681343 & 2.4 & Nicotiana tabacum ATP synthase alpha chain & TA13160_4097 & 0.4 & $\begin{array}{l}\text { Solanum tuberosum Adenylate kinase family-like } \\
\text { protein }\end{array}$ \\
\hline BP128932 & 2.4 & $\begin{array}{l}\text { Arabidopsis thaliana CRR4 (CHLORORESPIRATORY } \\
\text { REDUCTION 4) }\end{array}$ & AY741503 & 0.4 & $\begin{array}{l}\text { Nicotiana tabacum S-Adenosyl- L-methionine } \\
\text { methyltransferase (SAMT) mRNA }\end{array}$ \\
\hline EB102906 & 2.4 & Actinidia chinensis Plastid alpha-amylase & EB429936 & 0.5 & $\begin{array}{l}\text { Lycopersicum esculentum S-adenosyl-L- } \\
\text { methionine synthetase mRNA }\end{array}$ \\
\hline DV159621 & 2.4 & $\begin{array}{l}\text { Nicotiana tabacum NADPH: protochlorophyllide } \\
\text { oxidoreductase }\end{array}$ & & & \\
\hline EB426704 & 2.3 & Arabidopsis thaliana sugar isomerase (SIS8) & & & \\
\hline EH622880 & 2.2 & Nicotiana tabacum CP12 precursor & & & \\
\hline CV021666 & 2.2 & $\begin{array}{l}\text { Nicotiana tabacum chloroplast post-illumination } \\
\text { chlorophyll fluorescence increase protein mRNA }\end{array}$ & & & \\
\hline AJ001771 & 2.1 & $\begin{array}{l}\text { Nicotiana tabacum Glucose-6-phosphate } \\
\text { dehydrogenase }\end{array}$ & & & \\
\hline DV160944 & 2.0 & $\begin{array}{l}\text { Spinacia oleracea Ribose-phosphate } \\
\text { pyrophosphokinase } 4\end{array}$ & & & \\
\hline
\end{tabular}

Statistical significance was tested using Student's t-test $(p<0.05)$.

Fold change is indicated as a ratio of HC-Pro/WT calculated from normalized median intensity values $(n=3)$.

methylation of polygalaturonic acid) in these plants. The phenotype of these transgenic lines correlates well with our HC-Pro expressing tobacco plants indicating the central role of the transmethylation reactions in the plant development and differentiation.

\section{Protein profiles are strongly altered}

Both the energy deficiency and the altered transcript levels affect the level of protein synthesis. Therefore quantitative changes in the proteome were analysed using 2D-PAGE from the same leaf samples that were previously analysed in microarray. Results indicated dramatic changes in the protein composition between the wild type and HC-Pro expressing plants (Figure 4). A few spots of distinctly up- or down-regulated proteins, as visualized in the $2 \mathrm{D}$-acrylamide gels, were analysed by peptide sequencing after trypsin cleavage using LCESI MS/MS mass spectrometry. All identified protein spots turned out to be related to photosynthesis. The first identified, strongly up-regulated spot was RBCL. The transcript of the gene $R B C L$ was also up-regulated in leaves of the HC-Pro expressing plants (Table 8). Second identified spot was oxygen-evolving enhancer protein 1 (OEE33, gene name $p s b O$ ). Even though this protein was clearly down regulated, $p s b O$ was not found in the list of up- or down-regulated transcripts, while other transcripts encoding thylakoid lumen proteins ( $p s b P$ encoding a $29.8 \mathrm{kDa}$ protein and $p s b S$ gene encoding a $22 \mathrm{kDa}$ protein) were found to be downregulated. Third analysed, down-regulated spot was identified as tobacco CYP2 protein. This $20 \mathrm{kDa}$ protein has a high homology with AtCYP20-2 protein [42]. These peptidyl-prolyl cis-trans isomerases (PPIase) are redox-dependent proteins catalyzing folding of proteins in the thylakoid lumen of plant chloroplasts. Two chloroplast-directed tobacco proteins were identified in the fourth analysed, up-regulated spot; a $12 \mathrm{kDa}$ chloroplast protein $(\mathrm{CP} 12)$ and a photosystem I reaction center 


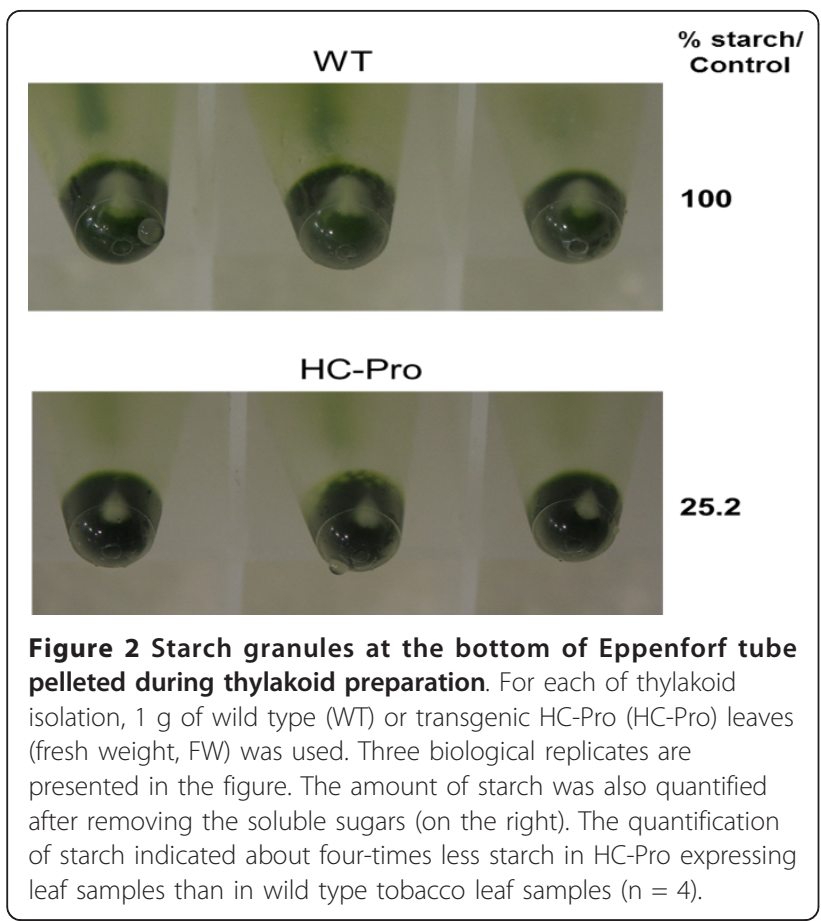

subunit (PsaN). The gene encoding for PsaN protein was also the most up-regulated gene in the list of photosynthesis-related genes (Table 8).

\section{Discussion}

This study provides a comprehensive picture of transcriptional changes in tobacco leaves and flowers due to expression of HC-Pro RSS derived from PVY. As far as

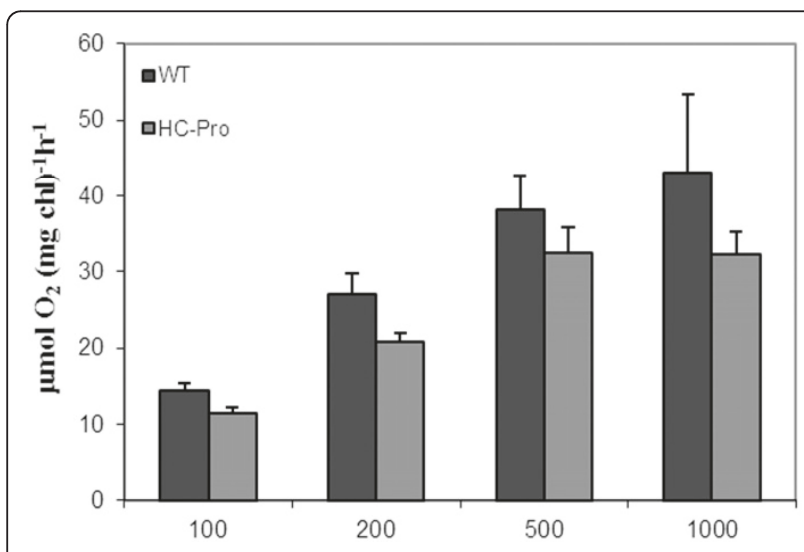

Light intensity ( $\mu \mathrm{mol}$ photons $\mathrm{s}^{-1} \mathrm{~m}^{-2}$ )

Figure 3 Light-responsive $\mathrm{O}_{2}$-evolution of photosystem II was measured of wild type (WT) and HC-Pro expressing plants. $\mathrm{O}_{2}{ }^{-}$ evolution was measured of freshly isolated thylakoid membranes using DCBQ as an electron acceptor. Standard error of mean is presented as bars abobe the columns ( $n=6$, consisting of three biological and two technical replicates). we know this is the first systemic analysis of viral RSSinduced gene expression alterations in tobacco host. HC-Pro RSS interferes with the silencing machinery.

The full genomic sequence of tobacco is not known, which limits the systemic analysis of transcriptional profiles in this species. However, a large collection of various EST and mRNA data is available and has been applied to construct a 44000 element microarray (Agilent) that provides the best possible approach for the systemic study of the tobacco gene functions today.

Previously, accumulation of small RNA pools have been systemically analysed via deep sequencing projects [43-45]. Expression of viral RSS in transgenic plants have been shown either to decrease the amount of miRNAs, or to reduce the activity of the silencing processes, which should lead to increase of the specific miRNAregulated target mRNAs. However, these regulatory defects seem to lead often to complex cascades of effects. MacLean \& coworkers [46] have shown that silencing-mediated regulatory reactions are highly interconnected and back-regulated and form intensive and multilayered regulatory networks. Indeed, we found in the list of genes modulated in our experiments many mRNAs that has been previously shown to contain target sites for miRNAs [43] and thus be post-transcriptionally regulated. The microarray analysis indicated that the expression levels of multiple genes (748 genes in leaves and 332 genes in flowers) were significantly altered in HC-Pro expressing transgenic plants.

\section{Defence and stress response in HC-Pro expressing plants}

The expression of HC-Pro RSS induced similar changes in gene expression profile as has been detected in virus infected plants $[15,26]$. We found that genes related to defence and both biotic and abiotic stress responses (jasmonic acid and ethylene responsive genes), transcriptional regulators (e.g. ERFs, RAV2), protein degradation related (proteasomal) proteins and proteases, and genes involved in photosynthetic reactions were altered in HC-Pro expressing tobacco plants in similar way as in Arabidopsis plants infected either by a TEV or CMV-Y $[15,22,23,25]$. The reason for this might be that the virus encoded RSSs interfere with long silencing mediated regulatory cascades, and their affects can be amplified through extensive regulatory networks. In conclusion, the expression of HC-Pro gene alone largely simulates the effects of a virus infection in plants, indicating that it is a major factor in viral pathogenicity.

HC-Pro RSS induced a general defense and stress response (e.g. PR-proteins) in transgenic tobacco plants (Tables 3). Liang et al. [47] have also shown that B3subgroup of AP2 transcription factors (ERF1, ERF3) regulates expression of pathogenesis-related genes (PR). We found these transcription factors up-regulated in both 

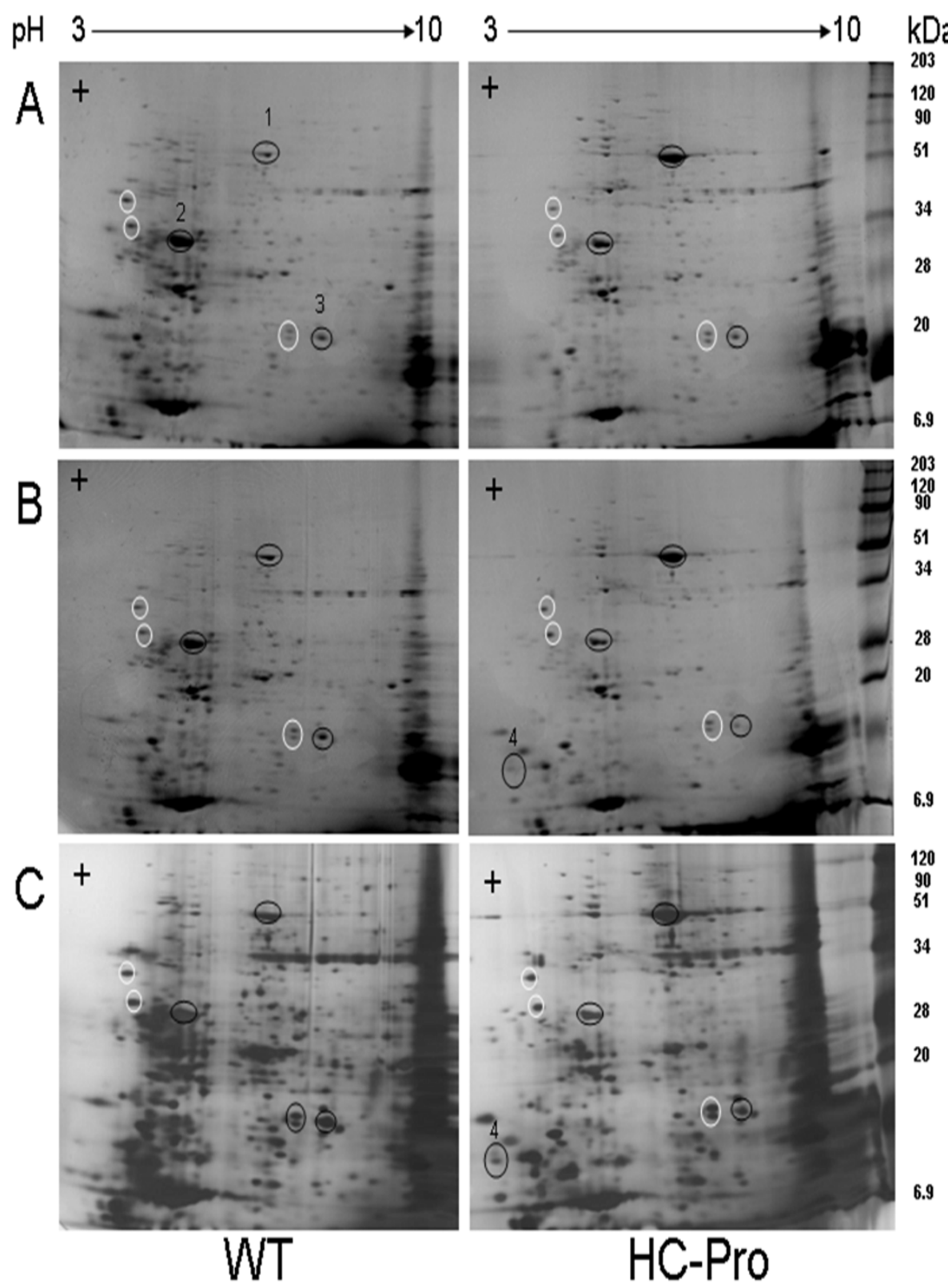

Figure 4 Proteome analysis of two biological replicates of wild type (WT) and HC-Pro expressing plants (HC-Pro). Proteins isolated from leaves were separated by using 2D-polyacrylamide gel electroforesis (2D-PAGE). Proteins in two isoelectric focused strips (WT and HC-Pro) were separated the second dimension in a large SDS-polyacrylamide gel. Upper gels (A and B) are stained using colloidal coomassie blue and the lower gel (C) using silver staining. White circles indicate control protein spots, whose intensity was not changed and black circles indicate protein spots that were either increased (1, RBCL and 4, PsaN, CP12) or decreased (2, OEE33 and 3, CYP2) in HC-Pro expressing plants. The identity of numbered protein spots was analysed using LC-ESI MS/MS mass spectrometry.

tobacco leaf and flower samples, which apparently lead to activation of other stress response genes. Salt, low temperature and dehydration responsive genes were induced, even thought the plants were not suffering from any kind of stress conditions. However, these stress responses might be also due to secondary effects from other primary causes, e.g. defects in photosynthetic light reactions and carbon metabolism, leading to shortage of sugar molecules comparable to cold or dehydration stress conditions [48].

Phenotypic changes related to changed gene expression The phenotypic changes found in transgenic HC-Pro expressing plants were induced most probably by changed expression of genes that regulate developmental differentiation. HC-Pro suppresses the activity of miRNAs, 
thus chancing the normal post-transcriptional regulation of various transcription factors that regulate developmental timing (flowering) and other developmental processes (leaf structure, stem internodes). Recently, Imaizumi [49] has reviewed genes involved in circadian clock and photoperiodism in A. thaliana, and their regulation by RNA-silencing. It has been previously shown that AP2 transcription factors (TOE1-3) are regulated by miR172, and a late-flowering mutant was produced by constitutive expression of the miR172 target gene TOE1 [50]. Many AP2-related transcription factors (e.g. ERF1 and RAV2) were enhanced in the HC-Pro expressing plants, possibly due to HC-Pro-mediated suppression of the miR172 function. It seems that miR172 is also regulated further by miRNA, namely miR156 [51].

Our results indicated that up-regulation of two ethylene responsive transcription factors (ERF1 and $R A V 2$ (TEMPRANILLO)) may have caused differential expression of defense-related genes and late flowering phenotype, respectively $[27,36,47,49,51,52]$. Late flowering phenotype in plants may be also due to problems in measuring the day length, which may induce problems in shifting from vegetative to reproductive phase of growth [33-35]. Expression of the whole set of genes encoding blue light receptors, transcription factors and proteasomal E3-ligases, all involved in induction of the flowering time locus $(F T)$ were altered (Table 7). The altered regulation of these genes in HC-Pro expressing plants may have postponed the plant's normal flowering time induction.

\section{The cysteine endopeptidase and thioredoxin properties of the expressed HC-Pro may also affect the protein profile}

Various characterized viral RSSs have different functional mechanisms [3,5,53-55]. In addition most of these proteins mediate also other functions which are essential for the viral life cycle and pathogenicity. Potyviral HCPro protein has domains of a cysteine endopeptidase and thioredoxin that may function in degradation of proteins containing cysteine residues, and changing the redox state of proteins (reduction of disulfide bonds to reduced cysteines) and these activities may have also contributed to the primary responses of HC-Pro expressing plants. Photosynthesis is the source of all the energy in plants by sugar metabolism, and it is known to be tightly regulated by redox states of the chloroplast proteins. The thioreduction of these proteins in cytoplasm could easily impair photosynthesis, and thereby lead to sugar starvation and further on, to altered regulation of the metabolic stress-related genes. The general stress response observed in the HC-Pro expressing plants can thus be due to direct alterations in the expression levels of some vital genes, and/or due to secondary effects, which again can be mediated by silencing suppression, cysteine endonuclease, thioreduction, impaired proteasomal functions or by all of those mechanisms. It appears that the disturbance of the normal chloroplast functions plays a central role in these response cascades.

The microarray data suggests that HC-Pro expressing tobacco cells have energy shortage, and the up-regulation of DIN genes might be one symptom of this. Normally, the DIN genes are induced under dark treatment or by various sugar metabolism defects [38,39], and both photosynhetic light and dark reactions are involved in regulation. Light activation curve of $\mathrm{O}_{2}$-evolution indicated decreased photosynthetic capacity in HC-Pro expressing transgenic plants (Figure 3), and the proteomic data also indicated that these plants indeed have problems in oxygen evolution in their PSII reaction center. To compensate this defect, genes encoding carbon fixation enzymes (RBCL and Rubisco subunit binding protein) were up-regulated. Also the production of storage sugar molecules was affected, as starch degradation was enhanced and synthesis reduced in HC-Pro expressing leaves (Table 8 and Figure 2). In addition, glycolysis was not used to gain energy from sugar molecules (e.g. repression of genes encoding PEP carboxylase and its activating kinase).

The genes regulating ATP synthesis in mitochondria and chloroplasts were clearly up-regulated, which may explain why many ATP-demanding systems, such as translation, were strongly altered (Figure 4). Another energy-dependent key process is the production of SAM [40], which is a general donor of methyl groups in the transmethylation reactions both in cytosol and in chloroplasts and mitochondria. A gene encoding plastid membrane-located SAMT protein was down-regulated more than two times in HC-Pro expressing plants, thus possibly affecting SAM levels in the chloroplasts, chloroplast biogenesis, and methylation reactions in chloroplasts [56]. High level of SAM is also needed for pectin synthesis of cell walls. Pectin is transported as highly methylated molecule into cell wall and must be demethylated by PME prior to insertion to cell wall. Due to decreased transmethylation capacity, the cell wall and especially pectin synthesis may have been affected.

The up-regulated PMEI and PGIP transcripts are both shown to be involved in resistanse against pathogenic attacks. An and co-workers [57] have recently shown that the PMEI is required for antipathogenic activity, basal disease resistance and abiotic stress tolerance, and that PMEI is clearly up-regulated in these biotic and abiotic stresses, and also by treatments with ethylene and jasmonic acid. Interestingly, PME is also known to be involved in viral tobacco mosaic virus (TMV) 
movement by binding to movement protein (MP) and assisting movement of viruses from cell to cell [58-60].

\section{Conclusions}

Multiple gene functions are affected in the $\mathrm{HC}$-Pro expressing transgenic plants, and these alterations induce a high stress status to the cells. Many of these stress responses appear to be interconnected, so that some to them are direct, but some are indirect, either caused by altered regulation of important transcription factors, induced by products of various signaling pathways i.e. ethylene and jasmonic acid pathways, or via the altered redox state of the cells. It appears that the sole $\mathrm{HC}$-Pro protease/silencing suppressor protein can offset the cellular regulatory network very drastically. Surprisingly the transgenic plants can still differentiate to fairly normal (even if malformed), seed producing phenotypes, indicating that the buffering capacity and redundancy of the genetic regulation is amazingly strong.

\section{Methods}

\section{Plant material}

The wild type tobacco (Nicotiana tabacum) and transgenic tobacco plants expressing HC-Pro transgene [10] were grown in greenhouse conditions at $60 \%$ relative humidity and $22^{\circ} \mathrm{C}$, with a day/night regime of $16 \mathrm{~h}$ light $\left(150 \mu \mathrm{mol}\right.$ photons $\left.\mathrm{m}^{-2} \mathrm{~s}^{-1}\right)$ and $8 \mathrm{~h}$ dark. Leaf samples (third leaf from the top) were taken from onemonth-old plants, the plants were at that time about 20 centimeters of height. Leaf and flower samples were taken from the same plant. Flower samples were taken one day prior to opening. Both leaf and flower samples were directly frozen in liquid nitrogen and stored at $-80^{\circ}$ C.

\section{RNA extraction, cDNA labeling and microarray hybridization}

Total RNA was isolated from leaves and flowers of wild type and transgenic plants using TRIsure-reagent (Bioline, UK) according to manufacturer's recommendations. Total RNA was further purified using RNeasy clean up column (QIAGEN inc. USA).

The cDNA labeling was performed using Agilent's Quick Amp Labeling kit for one-color (Product number 5190-0442). $700 \mathrm{ng}$ of purified total RNA was used to produce the Cy3 labelled cDNAs. All samples were processed together with Agilent's RNA spike kit (Product number 5188-5282). The quality of total RNA and labelled cDNA was checked using Agilent's 2100 bioanalyzer RNA 6000 Nano kit (Product number 5067-1511). The concentration of $\mathrm{Cy} 3$ labelled cDNA was also measured using NanoDrop ND-1000 spectrofotometer. 1.65 $\mu \mathrm{g}$ Cy3 labelled cDNA was hybridized on a Agilent's $4 \times$
$44 \mathrm{~K}$ tobacco chip (Design ID 21113) at $65^{\circ} \mathrm{C}$ over night $(17,5 \mathrm{~h})$ using solution provided in Agilent's Gene Expression Hybridization kit (Product number 51885242) according to manufacturer's recommendations.

The chips were washed after hybridization using ready-made solutions in Agilent's Gene Expression Wash Pack (Product number 5188-5327), in which the $0.005 \%$ Triton X-102 was added according to manufacturer's recommendations. The chips were further treated with Agilent's Stabilization and Drying solutions (Product number 5190-0423). The chips were scanned using Agilent Technologies Scanner, model G2565CA. Numeric data was produced using Agilent Feature Extraction software version 10.5.1.1. Grid: 021113_D_F_20080801; Protocol: GE1_105_Dec08; QC Metric Set: GE1_QCMT_Dec08.

The raw numerical data obtained after scanning microarray chips was analysed by using the $\mathrm{R}$ Project for Statistical Computing program ([61], Agi4 $\times 44 \mathrm{k}$ preprocess, Lopez-Romero, 2010). In order to compare intensity values of different samples (control, (6) vs. transgenic plant samples, (3)), the leaf samples were normalized together and the flower samples were as well normalized together. Normalization of three biological replicates was performed using median signal values and median background values. A background offset value (50) was added to prevent negative values during normalization. Normalization of the arrays was performed using a "quantile" parameter. All data handling was performed using Chipster, a visual program based on R Project for Statistical Computing program (Center of Scientific Calculating (CSC), Finland). The array results have been deposited into ArrayExpress with accession number E-MEXP-3105.

\section{Re-annotation of differentially regulated gene elements of $44 \mathrm{k}$ tobacco chip}

The tobacco genome is not totally sequenced like A.thaliana; instead the $44 \mathrm{k}$ tobacco chip is based on known tobacco genes, but also not so well annotated EST and cDNA sequence information. The differentially regulated genes that were up- or down-regulated more then two times in our tobacco $44 \mathrm{k}$ array were re-annotated using three different methods to get a proper functional annotation for the unknown gene names. In the first method the cDNA sequence was looked for similar DNA sequence using NCBI Blast Search. In the second method the cDNA sequence was translated to protein sequence (ExPASytranslate tool, SIB; Swiss Institute of Bioinformatics) and then homologous proteins were searched using FASTA/ SSEARCH/GGSEARCH/RCH - Protein Similarity Search (EMBL-EBI). In the third method, larger cDNAs were searched from Plant Transcript Assemblies Database (TIGR). Different tobacco EST and cDNA sequences are 
assembled to larger over-lapping cDNA sequences increasing the quality of annotation against other known plant cDNAs. Using these three methods, reliable annotation for most differentially regulated genes was obtained.

\section{Verification of differentially expressed genes}

The array results were verified by using RT-qPCR according to MIQE guidelines [62]. The RT-qPCR was performed from the same RNA samples as were previously used in microarray experiments. The cDNA was synthesized from $1 \mu \mathrm{g}$ of purified leaf or flower total RNA using RevertAid H-Minus M-MuLV reverse transcriptase according to manufacturer's recommendations (Product \# EPO451, Fermentas). Produced cDNA was diluted 1:15 and $3 \mu \mathrm{l}$ was used in RT-qPCR (Maxima SYBR Green/Fluorescein qPCR MasterMix (2X) (Product \# KO242, Fermentas). The gene specific reference and sample primers used in RT-qPCR are listed in Additional file 1 . For each three biological replicates, three-four technical replicates were run to minimize pipetting errors. RT-qPCR reactions were run in a 96well plate containing both wild type (reference) and HC-Pro transgenic samples. The RT-qPCR was performed using Bio-RAD's iQ5 machine. The results were calculated using the quantification cycle $\left(\mathrm{C}_{\mathrm{q}}\right)$ method (delta delta Cq) according to Bio-RAD's iQ5 default settings (see [62]). All primer pairs produced only one peak in DNA melting curves indicating high specificity of the primers. Standard error of mean (s.e) was also calculated of three biological replicates.

\section{Photosynthetic measurements}

Equal amount of intact wild type and HC-Pro transgenic tobacco leaves $(1.0 \mathrm{~g})$ were ground in an ice cold mortel in $4 \mathrm{ml}$ of thylakoid isolation buffer $(0.3 \mathrm{M}$ sorbitol, 50 $\mathrm{mM}$ Hepes/KOH pH 7.4, $5 \mathrm{mM} \mathrm{MgCl}_{2}, 1 \mathrm{mM}$ EDTA and $1 \%$ BSA). Suspension was filtered through a Miracloth and $2 \mathrm{ml}$ thylakoid suspension was pelleted in Eppendorf-centrifuge $12000 \times \mathrm{g}$ for 2 minutes (a picture was taken of thylakoids with a starch pellet, see Figure 2). The amount of starch was also quantified by using Megazyme total starch assay procedure (see details in Additional file 7). The pellet was resuspended into $100 \mu \mathrm{l}$ of $\mathrm{O}_{2}$-electrode measuring buffer $(0.3 \mathrm{M}$ sorbitol, $50 \mathrm{mM}$ Hepes/KOH pH 7.4, 5 mM MgCl $2,1 \mathrm{mM} \mathrm{KH}_{2} \mathrm{PO}_{4}$ ). Oxygen evolution was measured directly in a Clark type $\mathrm{O}_{2}$ electrode using 0.5 mM DCBQ as electron donor. The chlorophyll concentration was calculated according to Porra et al. [63]. Samples in the cuvette were quantified based on equal amount of total chlorophyll.

\section{Isolation of proteins, 2D-PAGE and Western blotting}

Protein samples of leaves from wild type and HC-Pro expressing transgenic plants were isolated concurrently with the RNA isolation using TRIsure-reagent (Bioline). The protocol was adapted from TRIzol (Invitrogen inc. USA) and performed according to manufacturer's recommendations. The protein concentration was measured using Lowry method. Proteins were first separated by Bio-Rad laboratories 7 cm IPG strips pH 3-10 according to manufacturer's recommendations. $250 \mu \mathrm{g}$ of protein was loaded per a strip. Strips containing wild type and transgenic HC-Pro focused protein samples were then run simultaneously in a large gel in Protean II apparatus (Bio-Rad) to produce a similar mobility of focused proteins of both strips. Protein gels were then fixed and stained in colloidal Coomassie blue stain (PageBlue staining kit, Fermentas) according to manufacturer's recommendations, destained and photographed. Some of the gels were also stained a second time with silver stain (PageSilver silver staining kit, Fermentas). Selected protein spots were taken from PageBlue stained gels and the protein identity was analysed after trypsin treatment using LC-ESI-MS/MS mass spectrometry in the proteomics unit (Turku Centre of Biotechology). Samples were analysed using Qstar i (Applied Biosystems/ MDS Sciex), coupled with a CapLC HPLC machine (Waters). Peptides were first loaded into precolumn $(0.3 \times 5 \mathrm{~mm}$ PepMap C18, LC Packings $)$ and then peptides were separated in a $15 \mathrm{~cm} \mathrm{C18} \mathrm{column}$ $(75 \mu \mathrm{m} \times 15 \mathrm{~cm}$, Magic $5 \mu \mathrm{m} 100 \AA$ C18, Michrom BioResources Inc. Sacramento, CA, USA) using a 20 min gradient. Peptide sequence search was performed using a Mascot program (v2.2.6) UniProt (release 2010_9) (see Additional files 8, 9, 10 and 11).

\section{Additional material}

Additional file 1: Primers for RT-qPCR and a table representing
expression of HC-Pro mRNA in transgenic plants measured by
using RT-qPCR.
Additional file 2: Supplemental Table 2. Normalized leaf microarray
data
Additional file 3: Supplemental Table 3. Normalized leaf microarray
data with FDR
Additional file 4: Supplemental Table 4. Normalized flower microarray
data
Additional file 5: Supplemental Table 5. Normalized flower microarray
data with FDR
Additional file 6: Supplemental Figure 6. A BOX-PLOT presentation of
data based on Supplemental Tables 3 and 5
Additional file 7: Method and results of starch quantification.
Additional file 8: Supplemental Table 8 . Peptide sequencing spot 1
(see Figure 4)
Additional file 9: Supplemental Table 9. Peptide sequencing spot 2
(see Figure 4)
Additional file 10: Supplemental Table 10. Peptide sequencing spot 3
(see Figure 4)
Additional file 11: Supplemental Table 11. Peptide sequencing spot 4
(see Figure 4)




\section{Acknowledgements and Funding}

The Finnish Microarray and Sequencing Centre (FMSC) at Turku Centre for Biotecnology is acknowledged for labeling the cDNAs, hybridizations, scanning the chips and producing the raw microarray data. Dr. Mika Keränen is acknowledged for helping data analysis and Center of Scientific Calculating (CSC, Espoo, Finland) for Chipster program. Turku Centre for Biotechnology (Proteomics Facility) is acknowledged for peptide sequence analysis using LC-ESI-MS/MS mass spectrometry. Professor Eva-Mari Aro is also acknowledged for critical reading of the manuscript. Research was supported by The Academy of Finland, grant numbers 127203 and 128943.

\section{Authors' contributions}

AJS grew and collected the plant material for the experiments. The experimental work and the reannotation of significantly altered trancripts were carried out by AJS and BJ together. AJS wrote and KL proof read the manuscript. All authors have read and approved the manuscript.

Received: 2 November 2010 Accepted: 20 April 2011

Published: 20 April 2011

\section{References}

1. Mlotshwa S, Pruss GJ, Vance V: Small RNAs in viral infection and host defense. Trends Plant Sci 2008, 13(7):375-382.

2. Ding SW, Voinnet O: Antiviral immunity directed by small RNAs. Cell 2007, 130(3):413-426.

3. Wadsworth S, Dunoyer P: Plant RNA-silencing immunity and viral counter-defence strategies. In Molecular Plant-Microbe Interactions. Edited by: Bouarab. Anonymous CAB international; 2009:1-35, pp.1-35.

4. Ruiz-Ferrer $V$, Voinnet O: Roles of plant small RNAs in biotic stress responses. Annu Rev Plant Biol 2009, 60:485-510.

5. Dunoyer P, Lecellier CH, Parizotto EA, Himber C, Voinnet O: Probing the microRNA and small interfering RNA pathways with virus-encoded suppressors of RNA silencing. Plant Cell 2004, 16(5):1235-1250.

6. Kasschau KD, Xie Z, Allen E, Llave C, Chapman EJ, Krizan KA, Carrington JC: P1/HC-Pro, a viral suppressor of RNA silencing, interferes with Arabidopsis development and miRNA unction. Dev Cell 2003, 4(2):205-217.

7. Cillo F, Mascia T, Pasciuto MM, Gallitelli D: Differential effects of mild and severe Cucumber mosaic virus strains in the perturbation of MicroRNA-regulated gene expression in tomato map to the $3^{\prime}$ sequence of RNA 2. Mol Plant Microbe Interact 2009, 22(10):1239-1249

8. Csorba T, Bovi A, Dalmay T, Burgyan J: The p122 subunit of Tobacco Mosaic Virus replicase is a potent silencing suppressor and compromises both small interfering RNA- and microRNA-mediated pathways. J Virol 2007, 81(21):11768-11780.

9. Lewsey M, Robertson FC, Canto T, Palukaitis P, Carr JP: Selective targeting of miRNA-regulated plant development by a viral counter-silencing protein. Plant J 2007, 50(2):240-252.

10. Siddiqui SA, Sarmiento C, Truve E, Lehto H, Lehto K: Phenotypes and functional effects caused by various viral RNA silencing suppressors in transgenic Nicotiana benthamiana and N. tabacum. Mol Plant Microbe Interact 2008, 21(2):178-187.

11. Chapman EJ, Prokhnevsky Al, Gopinath K, Dolja W, Carrington JC: Viral RNA silencing suppressors inhibit the microRNA pathway at an intermediate step. Genes Dev 2004, 18(10):1179-1186.

12. Lewsey M, Surette M, Robertson FC, Ziebell H, Choi SH, Ryu KH, Canto T, Palukaitis P, Payne T, Walsh JA, Carr JP: The role of the Cucumber mosaic virus $2 \mathrm{~b}$ protein in viral movement and symptom induction. Mol Plant Microbe Interact 2009, 22(6):642-654

13. Mlotshwa S, Schauer SE, Smith TH, Mallory AC, Herr JM Jr, Roth B, Merchant DS, Ray A, Bowman LH, Vance VB: Ectopic DICER-LIKE1 expression in P1/HC-Pro Arabidopsis rescues phenotypic anomalies but not defects in microRNA and silencing pathways. Plant Cell 2005, 17(11):2873-2885.

14. Anandalakshmi R, Pruss GJ, Ge X, Marathe R, Mallory AC, Smith TH, Vance VB: A viral suppressor of gene silencing in plants. Proc Natl Acad Sci USA 1998, 95(22):13079-13084.
15. Agudelo-Romero P, Carbonell P, de la Iglesia F, Carrera J, Rodrigo G, Jaramillo A, Perez-Amador MA, Elena SF: Changes in the gene expression profile of Arabidopsis thaliana after infection with Tobacco etch virus. Virol J 2008, 5:92.

16. Shiboleth YM, Haronsky E, Leibman D, Arazi T, Wassenegger M, Whitham SA, Gaba V, Gal-On A: The conserved FRNK box in HC-Pro, a plant viral suppressor of gene silencing, is required for small RNA binding and mediates symptom development. J Virol 2007, 81(23):13135-13148.

17. Merai Z, Kerenyi Z, Kertesz S, Magna M, Lakatos L, Silhavy D: Doublestranded RNA binding may be a general plant RNA viral strategy to suppress RNA silencing. J Virol 2006, 80(12):5747-5756.

18. Mallory AC, Ely L, Smith TH, Marathe R, Anandalakshmi R, Fagard M, Vaucheret H, Pruss G, Bowman L, Vance VB: HC-Pro suppression of transgene silencing eliminates the small RNAs but not transgene methylation or the mobile signal. Plant Cell 2001, 13(3):571-583.

19. Jin Y, Ma D, Dong J, Jin J, Li D, Deng C, Wang T: HC-Pro protein of Potato virus $\mathrm{Y}$ can interact with three Arabidopsis $20 \mathrm{~S}$ proteasome subunits in planta. J Virol 2007, 81(23):12881-12888.

20. Ballut L, Drucker M, Pugniere M, Cambon F, Blanc $\mathrm{S}$, Roquet F, Candresse $T$, Schmid HP, Nicolas P, Gall OL, Badaoui S: HcPro, a multifunctional protein encoded by a plant RNA virus, targets the $20 \mathrm{~S}$ proteasome and affects its enzymic activities. J Gen Virol 2005, 86(Pt 9):2595-2603.

21. Ascencio-lbanez JT, Sozzani R, Lee TJ, Chu TM, Wolfinger RD, Cella R, Hanley-Bowdoin L: Global analysis of Arabidopsis gene expression uncovers a complex array of changes impacting pathogen response and cell cycle during geminivirus infection. Plant Physiol 2008, 148(1):436-454

22. Endres MW, Gregory BD, Gao Z, Foreman AW, Mlotshwa S, Ge X, Pruss GJ, Ecker JR, Bowman $L H$, Vance $V$ : Two plant viral suppressors of silencing require the ethylene-inducible host transcription factor RAV2 to block RNA silencing. PLoS Pathog 2010, 6(1):e1000729.

23. Marathe R, Guan Z, Anandalakshmi R, Zhao H, Dinesh-Kumar SP: Study of Arabidopsis thaliana resistome in response to cucumber mosaic virus infection using whole genome microarray. Plant Mol Biol 2004, 55(4):501-520.

24. Whitham SA, Quan S, Chang HS, Cooper B, Estes B, Zhu T, Wang X, Hou YM: Diverse RNA viruses elicit the expression of common sets of genes in susceptible Arabidopsis thaliana plants. Plant J 2003, 33(2):271-283.

25. Babu M, Griffiths JS, Huang TS, Wang A: Altered gene expression changes in Arabidopsis leaf tissues and protoplasts in response to Plum pox virus infection. BMC Genomics 2008, 9:325.

26. Pompe-Novak M, Gruden $K$, Baebler Š, Krečič-Stres H, Kovač M, Jongsma M, Ravnikar M: Potato virus $Y$ induced changes in the gene expression of potato (Solanum tuberosum L.). Physiol Mol Plant Pathol 2005, 67(3-5):237-247.

27. Lorenzo O, Piqueras R, Sanchez-Serrano JJ, Solano R: ETHYLENE RESPONSE FACTOR1 integrates signals from ethylene and jasmonate pathways in plant defense. Plant Cell 2003, 15(1):165-178.

28. McGrath KC, Dombrecht B, Manners JM, Schenk PM, Edgar Cl, Maclean DJ, Scheible WR, Udvardi MK, Kazan K: Repressor- and activator-type ethylene response factors functioning in jasmonate signaling and disease resistance identified via a genome-wide screen of Arabidopsis transcription factor gene expression. Plant Physiol 2005, 139(2):949-959.

29. Jamet E, Albenne C, Boudart G, Irshad M, Canut H, Pont-Lezica R: Recent advances in plant cell wall proteomics. Proteomics 2008, 8(4):893-908.

30. Di Matteo A, Bonivento D, Tsernoglou D, Federici L, Cervone F: Polygalacturonase-inhibiting protein (PGIP) in plant defence: a structural view. Phytochemistry 2006, 67(6):528-533.

31. Ridley BL, O'Neill MA, Mohnen D: Pectins: structure, biosynthesis, and oligogalacturonide-related signaling. Phytochemistry 2001, 57(6):929-967.

32. Irshad M, Canut $H$, Borderies $G$, Pont-Lezica $R$, Jamet E: A new picture of cell wall protein dynamics in elongating cells of Arabidopsis thaliana: confirmed actors and newcomers. BMC Plant Biol 2008, 8:94

33. Sawa M, Kay SA, Imaizumi T: Photoperiodic flowering occurs under internal and external coincidence. Plant Signal Behav 2008, 3(4):269-271.

34. Sawa M, Nusinow DA, Kay SA, Imaizumi T: FKF1 and GIGANTEA complex formation is required for day-length measurement in Arabidopsis. Science 2007, 318(5848):261-265.

35. McWatters HG, Kolmos E, Hall A, Doyle MR, Amasino RM, Gyula P, Nagy F, Millar AJ, Davis SJ: ELF4 is required for oscillatory properties of the circadian clock. Plant Physiol 2007, 144(1):391-401. 
36. Castillejo C, Pelaz S: The balance between CONSTANS and TEMPRANILLO activities determines FT expression to trigger flowering. Curr Biol 2008, 18(17):1338-1343.

37. Jamet E, Roujol D, San-Clemente H, Irshad M, Soubigou-Taconnat L, Renou JP, Pont-Lezica R: Cell wall biogenesis of Arabidopsis thaliana elongating cells: transcriptomics complements proteomics. BMC Genomics 2009, 10:505.

38. Baena-Gonzalez E, Rolland F, Thevelein JM, Sheen J: A central integrator of transcription networks in plant stress and energy signalling. Nature 2007, 448(7156):938-942

39. Baena-Gonzalez E, Sheen J: Convergent energy and stress signaling. Trends Plant Sci 2008, 13(9):474-482

40. Moffatt BA, Stevens YY, Allen MS, Snider JD, Pereira LA, Todorova MI, Summers PS, Weretilnyk EA, Martin-McCaffrey L, Wagner C: Adenosine kinase deficiency is associated with developmental abnormalities and reduced transmethylation. Plant Physiol 2002, 128(3):812-821.

41. Weretilnyk EA, Alexander KJ, Drebenstedt M, Snider JD, Summers PS, Moffatt BA: Maintaining methylation activities during salt stress. The involvement of adenosine kinase. Plant Physiol 2001, 125(2):856-865.

42. Shapiguzov A, Edvardsson A, Vener AV: Profound redox sensitivity of peptidyl-prolyl isomerase activity in Arabidopsis thylakoid lumen. FEBS Lett 2006, 580(15):3671-3676.

43. Fahlgren N, Howell MD, Kasschau KD, Chapman EJ, Sullivan CM, Cumbie JS, Givan SA, Law TF, Grant SR, Dangl JL, Carrington JC: High-Throughput Sequencing of Arabidopsis microRNAs: Evidence for Frequent Birth and Death of MIRNA Genes. PLOS ONE 2007, 2:2.

44. Griffiths-Jones S, Saini HK, van Dongen S, Enright AJ: miRBase: tools for microRNA genomics. Nucleic Acids Res 2008, 36(Database issue):D154-8.

45. Fahlgren N, Sullivan CM, Kasschau KD, Chapman EJ, Cumbie JS, Montgomery TA, Gilbert SD, Dasenko M, Backman TW, Givan SA, Carrington JC: Computational and analytical framework for small RNA profiling by high-throughput sequencing. RNA 2009, 15(5):992-1002.

46. MacLean D, Elina N, Havecker ER, Heimstaedt SB, Studholme DJ, Baulcombe DC: Evidence for large complex networks of plant short silencing RNAs. PLoS One 2010, 5(3):e9901.

47. Liang H, Lu Y, Liu H, Wang F, Xin Z, Zhang Z: A novel activator-type ERF of Thinopyrum intermedium, TiERF1, positively regulates defence responses. J Exp Bot 2008, 59(11):3111-3120.

48. Sunkar R, Chinnusamy V, Zhu J, Zhu JK: Small RNAs as big players in plant abiotic stress responses and nutrient deprivation. Trends Plant Sci 2007, 12(7):301-309.

49. Imaizumi T: Arabidopsis circadian clock and photoperiodism: time to think about location. Curr Opin Plant Biol 2010, 13(1):83-89.

50. Jung JH, Seo YH, Seo PJ, Reyes JL, Yun J, Chua NH, Park CM: The GIGANTEA-regulated microRNA172 mediates photoperiodic flowering independent of CONSTANS in Arabidopsis. Plant Cell 2007, 19(9):2736-2748

51. Wu G, Park MY, Conway SR, Wang JW, Weigel D, Poethig RS: The sequential action of miR156 and miR172 regulates developmental timing in Arabidopsis. Cell 2009, 138(4):750-759.

52. Nakano T, Suzuki K, Ohtsuki N, Tsujimoto Y, Fujimura T, Shinshi H: Identification of genes of the plant-specific transcription-factor families cooperatively regulated by ethylene and jasmonate in Arabidopsis thaliana. J Plant Res 2006, 119(4):407-413.

53. Wang H, Buckley KJ, Yang X, Buchmann RC, Bisaro DM: Adenosine kinase inhibition and suppression of RNA silencing by geminivirus AL2 and L2 proteins. J Virol 2005, 79(12):7410-7418.

54. Voinnet $\mathrm{O}$ : Induction and suppression of RNA silencing: insights from viral infections. Nat Rev Genet 2005, 6(3):206-220.

55. Voinnet O: Post-transcriptional RNA silencing in plant-microbe interactions: a touch of robustness and versatility. Curr Opin Plant Biol 2008, 11(4):464-470.

56. Bouvier F, Linka N, Isner JC, Mutterer J, Weber AP, Camara B: Arabidopsis SAMT1 defines a plastid transporter regulating plastid biogenesis and plant development. Plant Cell 2006, 18(11):3088-3105.

57. An SH, Sohn KH, Choi HW, Hwang IS, Lee SC, Hwang BK: Pepper pectin methylesterase inhibitor protein CaPMEI1 is required for antifungal activity, basal disease resistance and abiotic stress tolerance. Planta 2008, 228(1):61-78

58. Chen MH, Sheng J, Hind G, Handa AK, Citovsky V: Interaction between the tobacco mosaic virus movement protein and host cell pectin methylesterases is required for viral cell-to-cell movement. EMBO J 2000, 19(5):913-920.

59. Dorokhov YL, Makinen K, Frolova OY, Merits A, Saarinen J, Kalkkinen N, Atabekov JG, Saarma M: A novel function for a ubiquitous plant enzyme pectin methylesterase: the host-cell receptor for the tobacco mosaic virus movement protein. FEBS Lett 1999, 461(3):223-228.

60. Pelloux J, Rusterucci C, Mellerowicz EJ: New insights into pectin methylesterase structure and function. Trends Plant Sci 2007, 12(6):267-277.

61. Gentleman RC, Carey VJ, Bates DM, Bolstad B, Dettling M, Dudoit S, Ellis B, Gautier L, Ge Y, Gentry J, Hornik K, Hothorn T, Huber W, lacus S, Irizarry R, Leisch F, Li C, Maechler M, Rossini AJ, Sawitzki G, Smith C, Smyth G, Tierney L, Yang JY, Zhang J: Bioconductor: open software development for computational biology and bioinformatics. Genome Biol 2004, 5(10): R80.

62. Bustin SA, Benes V, Garson JA, Hellemans J, Huggett J, Kubista M, Mueller R, Nolan T, Pfaffl MW, Shipley GL, Vandesompele J, Wittwer CT: The MIQE guidelines: minimum information for publication of quantitative realtime PCR experiments. Clin Chem 2009, 55(4):611-622.

63. Porra RJ, Thompson WA, Kriedemann PE: Determination of accurate extinction coefficients and simultaneous equations for assaying chlorophyll $\mathrm{a}$ and $\mathrm{b}$ with four different solvents: verification of the concentration of chlorophyll by atomic absorption spectroscopy. Biochim Biophys Acta 1989, 975:384-394.

doi:10.1186/1471-2229-11-68

Cite this article as: Soitamo et al:: HC-Pro silencing suppressor significantly alters the gene expression profile in tobacco leaves and flowers. BMC Plant Biology 2011 11:68.

\section{Submit your next manuscript to BioMed Central and take full advantage of:}

- Convenient online submission

- Thorough peer review

- No space constraints or color figure charges

- Immediate publication on acceptance

- Inclusion in PubMed, CAS, Scopus and Google Scholar

- Research which is freely available for redistribution

Submit your manuscript at www.biomedcentral.com/submit
C BioMed Central 